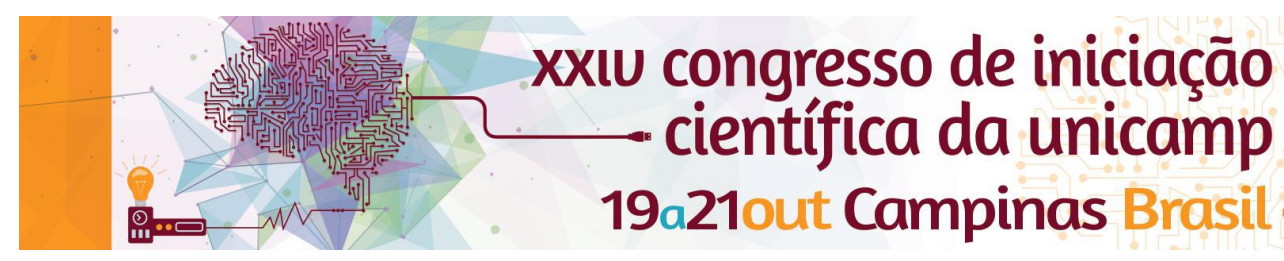

\title{
Avaliação heurística de games utilizando heurísticas de jogabilidade
}

\author{
Thiago A. M. Amendola*, Heiko H. Hornung
}

\section{Resumo}

Este trabalho tem como objetivo a análise e reflexão a respeito dos conjuntos de heurísticas para avaliação de jogos disponíveis na literatura. Estes conjuntos heurísticos atendem determinadas finalidades ou nichos específicos de aplicação. Por isso, é importante, porém não trivial, reconhecer quais desses conjuntos são mais apropriados para cada tipo de projeto ou escopo de teste. Além de levantar pontos de destaque em cada trabalho e apoiar potenciais avaliadores na escolha desses conjuntos, este trabalho também abre espaço para futuros estudos envolvendo a criação de novos conjuntos heurísticos que adotam novas áreas de abordagem e melhor qualidade nos testes.

\section{Palavras-chave: \\ Heurísticas de Jogo, Game Design, Avaliação Heurística.}

\section{Introdução}

Avaliar qualidades de um jogo através de métricas quantitativas e qualitativas é uma tarefa complexa. Por ser um objeto cultural e de entretenimento, encontrar meios capazes de avaliar um jogo em seus diferentes aspectos, como usabilidade e diversão, de maneira coerente é não trivial. Os métodos de avaliação heurística, originados no campo da interação humanocomputador, apresentam meios de mensurar qualidades de um software e, devido a sua praticidade e fácil adaptação, compõem uma ferramenta útil na avaliação de jogos.

O intuito deste trabalho é estabelecer um panorama dos modelos heurísticos para jogos disponíveis na literatura. Além disso, também foram avaliadas suas qualidades, limitações e contextos de uso, bem como recomendações de uso e a eficácia em aplicar mais de um modelo no teste de um jogo. Para isso, foi feita uma análise da literatura em busca destes conjuntos, bem como de conceitos relevantes para seu entendimento.

\section{Resultados e Discussão}

Cada método heurístico abordado tem como foco algum aspecto específico ou generalista. Três dos modelos abordados possuem uma abordagem generalista, visando a avaliação de qualquer tipo de jogo de modo integral. Outros três modelos analisados focam em determinados aspectos do jogo, mas são aplicáveis a qualquer tipo de jogo, enquanto outros 4 modelos visam atender um determinado nicho.

Modelos de heurísticas generalistas, como o de Desurvire e Wiberg ${ }^{1}$, são úteis quando o objetivo do teste é avaliar de modo geral um jogo. Costumam ser aplicáveis na maioria dos jogos, mas não avaliam aspectos únicos. Modelos focados, como o de Sweetser e Wyeth ${ }^{2}$, também são aplicáveis em grande parte dos jogos, mas focam sua análise em determinados aspectos do jogo. Como seus resultados são mais precisos, são úteis quando o objetivo do teste é avaliar apenas um aspecto, como usabilidade e diversão. Por fim, modelos de nicho, como os apresentados em Tsuda et al. ${ }^{3}$, não são aplicáveis a todos os jogos, mas são muito precisos na análise de um jogo de seu respectivo nicho, gerando resultados mais precisos e abragentes que os modelos generalistas.

A aplicação de mais de um modelo heurístico é recomendada, visto que pode encontrar problemas que cada modelo seria incapaz de encontrar isoladamente. Unir modelos generalistas ou de nicho a modelos focados podem garantir uma boa cobertura dos problemas.

Existe um consenso entre os autores de que estes modelos se tornam mais úteis quando os testes forem aplicados durante todo o processo de desenvolvimento do jogo, especialmente nas etapas iniciais, mitigando problemas em etapas menos custosas.

\section{Conclusão}

São necessários mais estudos e testes para definir com precisão a extensão e limites de cada conjunto de heurísticas, bem como interseções existentes e a utilidade na aplicação de mais de um modelo a um determinado caso. $\mathrm{O}$ estudo destes modelos ajudará no desenvolvimento de novos conjuntos heurísticos, menos redundantes, mais eficientes na detecção de problemas e capazes de abordar aspectos despercebidos atualmente.

\section{Agradecimentos}

Deixo agradecimentos ao CNPq pela bolsa cedida para a pesquisa e ao grupo Gamux, que têm fomentado trabalhos e pesquisas na área de jogos dentro da Unicamp.

\footnotetext{
${ }^{1}$ Desurvire, H. e Wiberg, C. Game usability heuristics (PLAY) for evaluating and designing better games: the next iteration. In On. Com. Soc. Comp. Springer Berlin Heidelberg, 2009, 557.

${ }^{2}$ Sweetser, P.; Johnson, D. e Wyeth, P. GameFlow heuristics for designing and evaluating real-time strategy games. In Proc. ACM 2009 Int. Conf. 2012.

${ }^{3}$ Tsuda, M.; Sanches, V. M.; Ferreira, T. G.; Otsuka, J. L. e Beder, D. M. Análise de métodos de avaliação de jogos educacionais. Em XIII SBGames, 2014, 158-166.
} 